\title{
Reproducibility of myocardial salvage index in acute myocardial infarction by cardiac magnetic resonance imaging - validation against an angiographic score

\author{
Holger Thiele*, Mahdi Sareban, Hubertus Engelhardt, Ingo Eitel, \\ Georg Fuernau, Matthias Gutberlet and Gerhard Schuler
}

Address: University of Leipzig - Heart Center, Leipzig, Germany

* Corresponding author

from 13th Annual SCMR Scientific Sessions

Phoenix, AZ, USA. 21-24 January 2010

Published: 21 January 2010

Journal of Cardiovascular Magnetic Resonance 2010, I2(Suppl I):P226 doi:10.I I86/I532-429X-I2-SI-P226

This abstract is available from: http://jcmr-online.com/content//2/SI/P226

(c) 2010 Thiele et al; licensee BioMed Central Ltd.

\section{Introduction}

Myocardial salvage assessed by cardiac magnetic resonance imaging (MRI) is a new technique which might be used as a surrogate endpoint to reduce the sample size in studies comparing different reperfusion strategies in infarction. So far reproducibility of myocardial salvage has not been evaluated appropriately.

\section{Purpose}

The aim of this trial was to assess the reproducibility of myocardial salvage assessment anf to validate it to an angiographic score.

\section{Methods}

In 20 patients with reperfused ST-elevation myocardial infarction breath-hold T2-weighted (area at risk [AAR]) and delayed enhancement (infarct size [IS]) images were acquired repeatedly on 2 consecutive days to assess myocardial salvage index (AAR-IS/AAR). Reproducibility, interobserver, and intraobserver variabilities were assessed and compared by Bland-Altman methods. In addition, the AAR at risk in \% of left ventricle (\%LV) determined by MRI was compared to an angiographic AAR score.

\section{Results}

The AAR determined by angiography was $31.0 \pm 10.0 \% \mathrm{LV}$ and by MRI $33.7 \pm 9.0 \%$; the MRI IS was $18.2 \pm 7.5 \% \mathrm{LV}$. The corresponding myocardial salvage index was $43.8 \pm$
22.5 (range 2.1-77.9). AAR difference (bias) between scan $\mathrm{I}$ and scan II was $-0.5 \% \mathrm{LV}$ and limits of agreement were \pm 5.9 LV. The results for IS were $0.1 \pm 2.2 \% \mathrm{LV}$ limits of agreement. The resulting bias for myocardial salvage index was -1.7 with limits of agreement of \pm 7.2 . Intra- and interobserver variability was low with a mean bias of -1.1 (limits of agreement \pm 4.7 ) and 0.3 (limits of agreement \pm $4.8)$, respectively.

\section{Conclusion}

Myocardial salvage index assessment by MRI is a reproducible and in comparison to angiographic scores an accurate tool in patients presenting with ST-elevation myocardial infarction. It might therefore serve as a valid surrogate endpoint to uncover advantages of new reperfusion strategies. 